\title{
TRES ARTÍCULOS DE LA CONSTITUCIÓN DE WEIMAR
}

\section{THREE ARTICLES FROM THE WEIMAR CONSTITUTION}

\author{
Ignacio Gutiérrez Gutiérrez \\ Universidad Nacional de Educación a Distancia
}

\begin{abstract}
SUMARIO: I. BERTOLT BRECHT, "TRES ARTÍCULOS DE LA CONSTITUCIÓN DE WEIMAR".- 1.1. Los preceptos.- 1.2. El poema.- 1.3. La traducción.- II. DISTANCIA.- 2.1. Teatro y Derecho.- 2.2. Derechos y realidad social.- 2.3. Pueblo y Estado. III.- WEIMAR - BRECHT.- IV. NOTA BIBLIOGRÁFICA.
\end{abstract}

Resumen: Weimar representa una herencia ambivalente: la de una Constitución relativamente lograda para una República que acabaría fracasando por razones en buena medida ajenas al texto aprobado en 1919; la de unos debates de gran altura en el plano de la teoría del Estado y del Derecho constitucional que, sin embargo, no lograron dar soporte a la pretensión normativa de la Constitución vigente. A partir de algunos fragmentos del texto de Weimar, la tensión entre, de un lado, su interpretación canónica por parte de Gerhard Anschütz y, de otro, su incorporación, de la mano de Bertolt Brecht, en el espacio cultural que él mismo configura con su obra y su presencia, quizá pueda arrojar luz sobre tal ambivalencia.

Abstract: Weimar supposed an ambivalente inheritance: a Constitution designed for a Republic which failed due to other reasons far from the Constition; and that of high level parliamentary speeches distant of the constitutional normative intentions. That ambivalence could be understood analyzing some constitutional fragments which show the tension between its interpretation by Gerhard Anschütz, and its incorporation to the cultural sphere defined by Bertrolt Brecht.

Palabras clave: Constitución de Weimar, distancia, cultura, Bertolt Brecht, Gerhard Anschütz.

Key Words: Weimar Constitution, distance, culture, Bertolt Brecht, Gerhard Anschütz

\section{BERTOLT BRECHT, "TRES ARTÍCULOS DE LA CONSTITUCIÓN DE WEIMAR".}

El poema de Bertolt Brecht "Tres artículos de la Constitución de Weimar" está fechado en 1931. Parecen en realidad tres canciones, aunque no tengamos noticia de que fueran musicadas; y glosan, en el estilo didáctico que entonces le era característico, tres preceptos concretos del texto constitucional. Comencemos por reproducirlos en la versión castellana de Miguel Sáenz, primero los preceptos constitucionales y luego el poema de Brecht. 


\title{
1. Los preceptos
}

Artículo 1. El Reich alemán es una República. El poder del Estado procede del pueblo.

Artículo 111. Todos los alemanes disfrutan de libertad de circulación en todo el territorio del Reich. Todos tienen derecho a establecerse y a residir en cualquier lugar del Reich, a adquirir alli bienes inmuebles y a ejercer su profesión. Las limitaciones requieren una ley del Reich.

Artículo 115. El domicilio de cualquier alemán le sirve de refugio y es inviolable. Las excepciones solo pueden basarse en una ley.

\section{E1 poema}

\author{
Artículo 1 \\ 1 \\ El poder del Estado procede del pueblo. \\ ... Pero ¿a dónde va? \\ Eso, ¿a dónde va? \\ ¡Tiene que ir a algún lado! \\ El policía sale de su casa. \\ ... Pero ¿a dónde va? \\ etc. \\ 2 \\ Mirad, ahora desfila el Patán. \\ ... Pero ¿a dónde desfila? \\ Ay, ¿a dónde desfila? \\ ¡Debe desfilar a algún lado! \\ Ahora da vueltas en torno a la casa, \\ ... Pero ¿hacia dónde da vueltas? \\ etc. \\ 3 \\ La autoridad del Estado se detiene de pronto. \\ Ve algo que está de pie. \\ ... ¿Qué ve que está de pie? \\ Ve algo que está de pie. \\ Y de pronto grita la autoridad del Estado \\ Grita: ¡Dispérsense! \\ ... ¿Dispersarse por qué? \\ Grita: ¡Dispérsense! \\ 4 \\ Ahí hay algo apelotonado \\ y algo pregunta: ¿por qué? \\ ¿Por qué pregunta por qué? \\ ¡Va y pregunta por qué! \\ Y claro, dispara la autoridad del Estado \\ y entonces ese algo cae desplomado. \\ ¿Qué es lo que se desploma ahí? \\ $¿ Y$ por qué se va desplomando?
}


5

La autoridad del Estado mira: hay algo por los suelos.

¡Hay algo que está por los suelos!

¿Qué es lo que está por los suelos?

Hay algo que está por los suelos.

Hay algo muerto y bien muerto

¡pero si es el pueblo!

¿Es eso realmente el pueblo?

Sí, eso es realmente el pueblo.

Artículo 111

1

Corre, corre, proletario, tienes derecho

a adquirir un terreno

a eso tienes derecho.

Derecho junto al Wannsee

derecho junto al Nikolassee.

Ahora ningún proletario debe tener ya hambre

tiene derecho a adquirir un terreno.

Tiene un derecho

no está mal hecho

puede adquirir algo.

2

Alto, alto proletario, ese terreno

lo ha adquirido ya uno.

A eso tiene derecho.

Derecho junto al Wannsee

derecho junto al Nikolassee.

Así que tienes que esperar a que muera.

Entonces lo habrá adquirido otro

habrá pagado

su derecho ha usado

¡Si no, lo habrías adquirido tú!

Artículo 115

1

También para un alemán hay refugios

porque en nuestra vida esclava son indispensables

indispensables.

Si tuviéramos una vivienda

sería esa vivienda inviolable

inviolable.

2

Nadie podría molestarnos en nuestra vivienda sería inmediatamente castigado como correspondiera correspondiera.

Esa vivienda nos pertenecería

si una vivienda nos perteneciera

perteneciera. 


\section{3}

Pero como por desgracia no conseguimos vivienda los sótanos y puentes nos resultan indispensables indispensables.

En cambio, si vivimos en la calle seremos, naturalmente, además vulnerables vulnerables.

\section{La traducción}

Traducir es a menudo una tarea compleja. En rigor: es siempre una tarea imposible. Cada lengua está indisolublemente ligada a sus propias tradiciones de pensamiento y de expresión; la traslación de los términos y de las proposiciones, por más precisión que logre incluso en la evocación de sus contextos inmediatos, nunca logrará incorporar la memoria acumulada en la dicción original. Los textos académicos alemanes del ámbito del Derecho constitucional o incluso de la Historia del Derecho pueden admitir una versión aproximada que los haga legibles en castellano, con el simple objetivo de la divulgación científica. Y, aún así, cada autor merece que se respeten sus elecciones de registro lingüístico, sus preferencias ritmicas, sus peculiaridades constructivas... Los retos que plantea un texto poético, sin embargo, son incomparablemente superiores. Quizá quepa disculpar la osadia de haberlos asumido, de nuevo con fines divulgativos, para ejemplificar con el Himno al Reich de Josef Magnus Wehner la retórica nacionalsocialista; pero ¿quién puede mirar de frente a Bertolt Brecht?

Miguel Sáenz ha traducido al castellano el teatro completo de Brecht, además de la mayor parte de la obra de Thomas Bernhard, numerosos libros de Günter Grass, la gran novela de Alfred Döblin sobre el Berlín de entreguerras (Berlin Alexanderplatz) y otros muchos textos de autores en lengua alemana o inglesa (aquí, en particular, a Salman Rushdie). Desde 1999 es miembro de la Academia alemana de lengua y literatura, con sede en Darmstadt, y de la española desde 2012. Pero no se trata aquí de recuperar la lista interminable de premios, reconocimientos y honores. Más significativo, para nuestro contexto, es recordar su condición de doctor en Derecho, especializado en Derecho del mar; como general auditor del Cuerpo Jurídico de la Defensa ocupó el puesto de Fiscal de la Sala Quinta del Tribunal Supremo; y, como traductor especializado en Derecho, ha trabajado en las Naciones Unidas y para otras muchas organizaciones internacionales.

Con espontánea generosidad aceptó de inmediato la tarea propuesta por un desconocido profesor de Derecho constitucional de traducir el mencionado poema de Brecht, del que no parece existir una versión previa en castellano. Incluso mostró cierto entusiasmo por el reto, pretextando que nunca había traducido al Brecht poeta; algo que resultaba evidentemente impreciso: aunque es cierto que en los libros de poesía de Brecht en castellano aparecen como traductores (junto con otros) escritores de la talla de Jesús López Pachecho, Jesús Munárriz o Jenaro Talens, una parte significativa de la producción poética de Brecht se inserta en las piezas teatrales que ha traducido Miguel Sáenz. 
También aceptó ofrecer una traducción de los artículos correspondientes de la Constitución de Weimar; porque, naturalmente, se hacía necesario compaginar el texto jurídico y la glosa literaria. No siempre resultaba fácil. Por ejemplo, en el art. 1 de la Constitución de Weimar y en el primer verso de la canción correspondiente se puede leer en la lengua original: "Die Staatsgewalt geht vom Volke aus". La opción a favor del verbo "proceder", en lugar de "emanar", atiende a las exigencias específicas del poema. Es cierto que "emanar" aprovecharia la evocación del art. 1.2 CE, pero haría confuso el paralelismo con el inmediato "el policía sale de su casa": "proceder" y "salir de" son aquí equivalentes más intuitivos. Por su parte, el policía es, en las estrofas tercera y quinta, "la autoridad del Estado", no "el poder del Estado", aunque se pierda aquí la equivalencia textual; porque, a su vez, la tradición constitucional no permite referirse a "la autoridad del Estado" en el art. 1 del texto constitucional. Esas y otras cuestiones de la traducción, de Alemania, de la República de Weimar y de su propia trayectoria vital he tenido el privilegio de comentar con Miguel Sáenz con ocasión de este ensayo.

\section{DISTANCIA}

\section{Teatro y Derecho}

Marcel Reich-Ranicki, el célebre "Papa de la literatura alemana", profetizó que, por mucha que fuera su trascendencia en el mundo del teatro, Brecht sería inmortal gracias a su poesía. Y subrayó también la frecuencia con la que esa poesía se aleja de los innovadores postulados teóricos desarrollados por el autor para su dramaturgia: la poesia de Brecht se atiene muy a menudo a formas, temas y recursos clásicos; que, en cualquier caso, parecen recién acuñados por su voz magistral, tan decisiva en la renovación de la lengua alemana.

Este poema, sin embargo, enlaza directamente con el teatro didáctico que Brecht empieza a escribir y dirigir a finales de los años 20; las canciones parecen sacadas de alguna de aquellas escenas, quizá ya con la música de Hanns Eisler, formado en la escuela dodecafónica de Arnold Schönberg y colaborador de Brecht a partir de 1930. Brecht usaba allí tales canciones como un medio más destinado a lograr el fundamental V-Effekt, el Verfremdungseffekt o efecto de distanciamiento, con el que pretendía pretendia que el espectador, en lugar de identificarse emocionalmente con la escena, la percibiera como instancia crítica respecto de la realidad cotidiana.

Por cierto: una distancia de ese tipo es, como ha subrayado SchmidtAßmann, inherente al Derecho moderno. Tanto la ley general y abstracta como el juez independiente e imparcial se mantienen alejados del caso concreto. El propio Brecht, en una de las historias del señor Keuner, evoca la distancia propia de la jurisdicción en términos que recuerdan las pretensiones de su escenografia:

"El señor K. mencionó frecuentemente como modélica en cierto modo, una disposición jurídica de la antigua China, conforme a la cual, en caso de procesos importantes, los jueces eran traídos de provincias remotas (...) Estos jueces traídos desde lejos tampoco conocian por experiencia cotidiana los usos y circunstancias del lugar. La injusticia con frecuencia se convierte en norma jurídica simplemente 
porque se repite a menudo. Los recién llegados debían requerir nueva información sobre todo, y de ese modo percibian cuanto había de sorprendente".

En términos teóricos, tal distancia tiene carácter estructural. Se puede radicalizar como separación entre ser y deber ser, y así se hace también cuando se alude al carácter contrafáctico de las normas jurídicas. Pero igualmente cabe relativizarla, apelando a las conexiones entre la norma jurídica y el complejo formado por todas sus condiciones de realización, que a la postre determinan su relevancia; unas conexiones, en cualquier caso, que cabe concebir de muy diversos modos.

\section{Derechos y realidad social}

Brecht, de acuerdo con el giro que impuso a su obra el exhaustivo estudio de Marx que emprendió tras instalarse en Berlín en 1924, subraya en este poema la distancia entre las relaciones sociales efectivas y su recubrimiento ideológico por parte de la superestructura jurídica. Las dos últimas canciones evocan inmediatamente la crítica de Marx al reconocimiento de derechos por parte de las constituciones liberales decimonónicas, tal y como puede leerse en el propio Manifiesto Comunista:

"Os escandalizáis de que queramos suprimir la propiedad privada. Pero, en vuestra sociedad actual, la propiedad privada está suprimida para nueve décimas partes de sus miembros; existe precisamente gracias a que no existe para el noventa por ciento. Nos reprocháis, pues, que queramos suprimir una propiedad que presupone, como condición necesaria, la falta de propiedad de la inmensa mayoría de la sociedad".

El derecho de adquirir terrenos, por tanto, es ilusorio para quien percibe por su trabajo solo lo imprescindible para garantizar la subsistencia y reproducción de la clase a la que pertenece. La inviolabilidad del domicilio es inútil para quien carece de él; solo sirve para dejar en evidencia su vulnerabilidad. Las libertades constitucionales son percibidas como palabras huecas por quienes no tienen a su alcance los presupuestos materiales imprescindibles para su ejercicio: cuando no todos tienen una vivienda, cuando escasean los terrenos disponibles, cuando no hay dinero para comprarlos. Si esa percepción se convierte en dominante, la Constitución misma se ve reducida a falacia.

Podemos constatar que Brecht se limita aquí a evocar libertades civiles clásicas en su clásica concepción burguesa. El programa social de la Constitución de Weimar no le interesa. Y quizá no sea solo por razones estratégicas o ideológicas: porque la promesa de reconciliación social que contiene el texto de Weimar pudiera desmentirle o porque desprecie su talante meramente "revisionista". También cabe considerarlo como un efecto de la distancia, esta vez temporal, entre la Constitución adoptada en 1919 y la Alemania de 1931 en la que Brecht escribe sus versos; la distancia entre el nacimiento de una esperanza y la experiencia de su frustración. Las circunstancias económicas y sociales, politicas y también jurídicas de la República de Weimar habían logrado devaluar el amplio contenido social de la Constitución. Sólo más tarde, bajo la Ley Fundamental de 1949, se irán 
desarrollando garantías para la realización del programa ahora meramente implícito en el postulado del Estado social, que convierte las libertades constitucionales en un mandato a los poderes públicos para procurar las condiciones materiales que permitan su ejercicio efectivo por parte de todos. De este modo se sutura, aunque de modo siempre parcial y precario, una de las brechas entre la norma y la realidad.

Tal reconfiguración de los derechos fundamentales, sin embargo, no parecía imaginable para la doctrina jurídica más influyente de la época de Weimar; en la que, por generalizado que estuviera el reconocimiento de su brillantez y de su profundidad, no podemos contar a Hermann Heller, que justo en 1930 habia acuñado la expresión "Estado social de Derecho": su origen judio, su compromiso político y su talante personal lo colocaban en una posición marginal. No era imaginable, decimos, para Schmitt, empeñado en estilizar el Estado burgués de Derecho para confrontarlo más abiertamente con un modelo igualmente estilizado de democracia excluyente; ni siquiera para Smend, cuya materialización del modelo adopta la forma ideal de los valores, no la real de los presupuestos. Menos aún, claro está, para el positivismo que se considera hegemónico en la dogmática constitucional, aunque dicha orientación metodológica presentara en realidad variantes significativas y la teoría del Estado, de la Constitución y del Derecho politico estuvieran ya determinadas por la creciente beligerancia de las no menos diversas posiciones antipositivistas.

Los elementos fundamentales del positivismo dominante pueden considerarse representados por el comentario sistemático a la Constitución de Gerhard Anschütz, que sigue valiendo como modelo canónico de este tipo de obras. En su análisis de la Segunda Parte de la Constitución de Weimar parte de la diferenciación básica entre normas directa e inmediatamente aplicables y otras que son meros principios orientativos para la legislación futura. Su comentario al art. 111 se limita luego a señalar los antecedentes de las correspondientes garantías en el Derecho ordinario y las restricciones legales vigentes, que en absoluto cuestiona; también subraya que las restricciones de la libertad de circulación, en cuanto derecho reservado a los alemanes, han de tener apoyo en leyes del Reich, mientras que los extranjeros quedan sometidos en este ámbito a las normas de policía de los Länder. Igualmente breve es su comentario al art. 115: la inviolabilidad del domicilio es una idea liberal clásica con numerosos precedentes; comprende la vivienda, los espacios dedicados al trabajo y, en general, cualquier posesión pacífica; las excepciones basadas en la ley comprenden también las medidas adoptadas para poner las viviendas particulares al servicio de fines públicos o de terceros, como ocurre en los casos de escasez de vivienda... Lo más significativo es que el artículo 115 se concibe expresamente no como limite al legislador, sino a la administración, que necesita habilitación normativa para intervenir en el derecho; una habilitación que, en cualquier caso, le pueden conceder las leyes o los reglamentos habilitados por las mismas, pero también incluso las cláusulas generales del Derecho de policía de los Länder, a veces de carácter meramente consuetudinario. No es significativo aquí, pues, que el derecho esté nominalmente consagrado para los alemanes; en realidad, el art. 111 constituía, en este sentido, una de las excepciones a la regla general de la igual eficacia de los derechos constitucionales para todos, alemanes y extranjeros. 
Anchütz termina así extendiendo al art. 115 de la Constitución de Weimar las consideraciones de Richard Thoma acerca de la irrelevancia jurídica de la consagración de la libertad personal en el art. 114.1. Porque, en efecto, en ausencia de una garantía de intangibilidad del contenido esencial de los derechos fundamentales y del correspondiente control de constitucionalidad de las leyes, los derechos fundamentales, incluso en la medida en que resultan directamente aplicables, se limitan a su juicio a repetir lo que deriva, sin más, del principio de legalidad de la administración inherente al Estado de Derecho, conforme al cual no caben más limitaciones en la libertad natural que las previstas en las leyes.

Los derechos constitucionales, pues, no solo carecían de relevancia práctica para buena parte de la población, como señalaba Brecht; tampoco les atribuía una trascendencia particular, al menos en principio y para la vida jurídica cotidiana, la doctrina mayoritaria en el ámbito especializado del Derecho público. Es verdad que tampoco esa doctrina pudo dar la espalda al hecho objetivo de que la Constitución dedicara toda su segunda parte a los derechos y deberes fundamentales de los alemanes. Fue reconociendo al menos el valor simbólico de la proclamación de derechos, debatiendo incluso sobre su eventual operatividad como limite para el legislador. Pero, precisamente en ese terreno, los derechos fundamentales y las normas de Derecho objetivo que los acompañaban (en particular, las garantías institucionales) en absoluto se concebían como un impulso vinculante para la acción pública, por ejemplo con la finalidad de poner a disposición de todos las bases materiales imprescindibles para su ejercicio, sino como un dique frente a su intervención en estructuras sociales e instituciones juridicas ya arraigadas.

\section{Pueblo y Estado}

Más significativo aún es el comentario de Anschütz al art. 1 de la Constitución de Weimar, especialmente si tenemos en cuenta el compromiso declarado de su autor con el régimen constitucional, definitivamente acreditado por los motivos que alega al solicitar la jubilación anticipada el 31 de marzo de 1933.

Conviene recordar que Hitler había sido nombrado canciller el 30 de enero; el 4 de febrero se aprueban las primeras medidas contra comunistas y socialistas, limitando también las libertades de reunión, expresión y prensa; el 28 de febrero, con ocasión del incendio del Reichstag, se suprimen definitivamente los derechos fundamentales; el 22 de marzo se abre el primer campo oficial de concentración en Dachau; la célebre ley de habilitación de plenos poderes tiene fecha del día 24 de marzo. Pues bien, el prólogo a la cuarta revisión de su comentario a la Constitución, que se publica como décimocuarta edición, está fechado en febrero de 1933; y en él advierte ya Anchütz de los riesgos que amenazan los fundamentos y la fuerza vinculante de la Constitución: sus enemigos podrian suprimirla de hecho o reformarla por vías legales o ilegales hasta reducir a mero valor histórico el trabajo que, pese a todo, se anima a presentar forzando la esperanza y confiando en la propia elasticidad del texto constitucional. Pero, finalmente, el 31 de marzo escribe:

"Mi tarea docente comprende en primer lugar el Derecho político alemán. De acuerdo con la convicción que siempre me ha guiado, y para la que pido la comprensión del Sr. Ministro, esta materia 
plantea a los docentes no solo exigencias propias de la ciencia del Derecho, sino también de naturaleza política. La tarea del profesor de Derecho político no es solo transmitir a los estudiantes el conocimiento del Derecho politico alemán, sino también educarlos en la orientación y el espíritu del orden constitucional vigente. Para ello es necesario que el docente tenga un alto nivel de compromiso personal con el orden estatal. Mi deber de sinceridad me impone reconocer que en estos momentos no estoy en condiciones de aportar ese compromiso con el nuevo Derecho político alemán que ahora se está configurando".

Pues bien: un jurista eminente, comprometido con el régimen constitucional, dedica casi plenamente el comentario al art. 1 de la Constitución de Weimar a subrayar la trascendencia que tiene para la concepción constitucional de las relaciones entre el Reich y los Länder el hecho de que, frente a lo que se decía en el primer borrador de Constitución, no "todo" el poder del Estado reside en el pueblo "alemán". Aquel texto inicial, conforme a la interpretación del propio Hugo Preuß, impedía considerar el poder de los Länder como originario, pues solo el del Reich surge del pueblo alemán en su conjunto. La redacción definitiva, sin embargo, se limita a decir: "El poder del Estado procede del pueblo"; con ella cabe entender que el poder del Reich procede del pueblo alemán, mientras que el poder de los Länder emana de su propio pueblo. Para Anschütz es este el rasgo decisivo de la cualidad estatal de los Länder; que no se caracteriza por el poder soberano, que sin duda no les corresponde, sino por el poder originario. Y, en consecuencia, también es ese el fundamento de la naturaleza federal de Reich.

Anschütz señala igualmente, por supuesto, que la expresión recoge el principio fundamental de toda democracia: la soberanía popular; e identifica aquí el pueblo con el cuerpo electoral, sin pensar que pudiera tener relevancia en este punto el hecho de que el texto definitivo hubiera suprimido el adjetivo "alemán" que figuraba en el primer borrador. El cambio del verbo, producido ya en la última fase de la elaboración de la Constitución, se considera intrascendente, "sin importancia objetiva": el poder del Estado ya no "reside en el pueblo", sino que "procede de" él. Pero es justo esta expresión la que estimula la reflexión de Brecht.

Su primera canción, en efecto, describe un significativo recorrido circular: el poder del Estado procede del pueblo y ciertamente retorna a él, pero en forma de aniquilación. La democracia constitucional, entiende Brecht, se agota en la primera referencia de Lincoln (gobierno desde el pueblo); porque, tras saltar sobre la segunda (el policía no es, desde luego, autoridad ejercida por el pueblo), se pervierte la tercera: el poder del Estado se proyecta como violencia contra el pueblo.

El poder del Estado, pues, procede del pueblo; pero de manera inmediata aparece encarnado por un policía, el Patán (das große Trumm). Para subrayar su distancia con el pueblo, al que ese poder habrá de volver en forma de violencia, Brecht dedica al recorrido varias estrofas. Las preguntas denotan aquí perplejidad. La incomprensión respecto del camino que está recorriendo el poder es un indicio de alienación: el comportamiento del poder que el pueblo ha generado resulta ininteligible para el propio pueblo. Pero tampoco el poder acierta a identificar al pueblo no ya como fundamento de su poder, sino tampoco como destinatario del mismo: solo ve "algo" objetivo y genérico, que "naturalmente" ha 
de ser enfrentado con la violencia; esta aparece así, en términos familiares para la clásica teoría del Estado, como la manifestación característica del poder público.

Con todo ello, Brecht llama la atención sobre lo que entonces parecía evidente no solo al conjunto de la población, sino también para los juristas especializados en Derecho público, fuertemente anclados a las elaboraciones dogmáticas tradicionales: el Estado es una entidad objetiva que trasciende la forma política, democrática o no, que pueda darle su Constitución; está encarnado por el funcionariado y el ejército, y tiene como finalidad primordial la garantía de la seguridad. Para un Estado así configurado, el pueblo aparece solo como objeto de su poder de policia, concebido en Alemania en términos muchos más amplios de los que en España evoca el término.

Por supuesto que esta construcción convencional no carecía de alternativas teóricas. El reto de formar unidad política en las nuevas circunstancias históricas, ante las tensiones que amenazaban la subsistencia efectiva del propio Estado y desde la democracia como único principio legitimador, dificilmente podía afrontarse con la simple afirmación de la personalidad jurídica del Estado y la consecuente construcción jurídica. Las propuestas novedosas más significativas se articulan en torno a las nociones jerarquía (Kelsen), decisión (Schmitt), integración (Smend) y organización (Heller), que se suman a otros enfoques anteriores tampoco convencionales, como los de Preuß o Triepel. Pero el trabajo institucionalizado de los juristas apenas se veía afectado por estas disputas metodológicas de altura.

De nuevo aquí podemos señalar que Brecht omite una parte significativa del relato: justamente la que se refiere al proceso de emanación del poder del Estado. La Constitución de Weimar, en este sentido, ofrecía un diseño complejo: elección por voto directo del Reichstag y del Presidente del Reich, mientras que el Gobierno nombrado por este depende también de la confianza del Reichstag; los parlamentos de los Länder, también elegidos de modo directo, participan en la legislación del Reich a través del Reichsrat; a esa legislación parlamentaria se añade la posibilidad de legislar a través de referendum y por reglamentos de necesidad adoptados por el Presidente del Reich. Tales previsones de la Constitución de Weimar, referidas a las procesos e instituciones de legitimación del poder del Estado que concretan, desarrollan y configuran el principio democrático, habian procurado salvar la distancia estructural en ese tramo ascendente de la vida democrática. Pero lo cierto es que, una vez más, la distancia temporal entre 1919 y 1931 juega aquí un papel decisivo.

Merece la pena recordar que desde marzo de 1930, con la caída del Gabinete encabezado por el socialdemócrata Hermann Müller, el nuevo Canciller Heinrich Brüning, del Zentrum católico, contaba solo con la confianza del Presidente del Reich Paul von Hindenburg; este le había vetado formar coalición con los socialdemócratas, privándole así de la posibilidad de apelar al respaldo expreso del Reichstag. Los socialdemócratas, sin embargo, "toleraron" tal Gobierno presidencial y se abstuvieron en las sucesivas votaciones de censura, lo que permitió a Brüning gobernar hasta mayo de 1932 mediante reglamentos de necesidad: el Presidente adoptó en ese tiempo un total de 62, y retiró precisamente la confianza a Brüning mediante el anuncio de que no aprobaría más. Ello afectaba en muy primer lugar al previsto para reducir las ayudas a los grandes propietarios de Prusia Oriental, entre los que estaba el propio Hindenburg. El objetivo de tal reglamento era forzar la subasta pública de esas 
propiedades agrarias, que finalmente habria de adquirir el Estado para destinarlas al asentamiento de quienes en las ciudades habian quedado sin trabajo a causa de la crisis económica. Pero tampoco esta vez se hubiera pensado que de este modo se dotaban los presupuestos reales del ejercicio del art. $111 \mathrm{de}$ la Constitución, al que ya nos hemos referido; se trataría, todo lo más, de una medida amparada por el art. 155 de la Constitución.

\section{WEIMAR - BRECHT}

Hemos mencionado reiteradamente la distancia temporal entre 1919 y 1931; un periodo que cambió profundamenta la percepción de la Constitución de Weimar, pero también la de la propia ciudad.

A comienzos de 1919, cuando se decidió que la Asamblea Nacional se reuniera en Weimar, la ciudad representaba fundamentalmente el llamado clasicismo alemán; que, por supuesto, no es solo una etiqueta solemne para la relación de amistad entre Goethe y Schiller. El periodo clásico no puede describirse sin mencionar también a Wieland y a Herder, así como a las numerosas personalidades que, comenzando por el propio Napoleón, acudian al encuentro con Goethe. Weimar había ocupado ya un lugar prominente en los inicios de la reforma luterana y también había propiciado la maduración artística de Bach, establecido en la corte ducal durante nueve años. Después de la muerte de Goethe, la presencia de Liszt en Weimar o las Escuelas de Bellas Artes y de Artes Aplicadas habian mantenido la ciudad en el corazón de la vida cultural alemana; su unificación en abril de 1919, en pleno proceso constituyente, con la pronto celebérrima rúbrica Bauhaus y bajo la dirección de Walter Gropius, supuso un hito adicional en esta trayectoria.

Berlin, por su parte, a la cabeza de Brandenburgo, de Prusia y, desde 1871, también del Imperio, se había convertido desde noviembre de 1918 en la capital de la agitación. Desde la doble proclamación de la República el día 8 de ese mes, por parte de Philipp Scheidemann y de Karl Liebknecht, cada modulación de las respectivas posiciones políticas implicaba un tumulto. La revuelta espartaquista había sido sofocada solo cuatro días antes de la celebración de las elecciones, con una actuación represora que había culminado en el asesinato de Rosa Luxemburg y Karl Liebknecht el 15 de enero. La decisión de que la Asamblea Nacional se reuniera en Weimar había sido ya adoptada el día anterior.

Weimar está a unos $300 \mathrm{~km}$. de Berlín, pero ambas ciudades se encontraban ya entonces bien comunicadas; desde el 6 de febrero de 1919, coincidiendo con la apertura de las sesiones de la Asamblea Nacional, dos vuelos diarios unían ambas ciudades: se trataba de la primera línea aérea civil dentro del país. La distancia entre Weimar y Berlin, sin embargo, era casi infinita en el plano simbólico: la que media entre la Alemania ilustrada y la Alemania industrial, entre la cultura y el poder militar, entre la armonía espiritual y el conflicto de clases, entre los valores perennes y la fugacidad. En la decisión de reunir la Asamblea Constituyente en Weimar latia, por tanto, no solo el sensato recelo frente a la inestabilidad politica de la capital, sino también la intención de dotar a la obra prevista de un muy determinado fundamento simbólico. Pero lo cierto es que también Weimar presentaba en ese aspecto rasgos contradictorios, y su referencia valorativa no tardó en marchitarse. 
El Gran Ducado de Sajonia-Weimar-Eisenach, resultado de las prácticas hereditarias de la linea ernestina de la casa Wettin, comprendía tres unidades territoriales diferentes y diversos enclaves en otros Estados cercanos; todavía en 1919 representaba, junto con el resto de pequeños Estados de Turingia, la incapacidad alemana para articular racionalmente el poder político. Con menos de 40.000 habitantes, Weimar no se había alejado aún del juicio que le mereció a Madame de Staël a comienzos del siglo XIX: más que una pequeña ciudad, un gran palacio; o quizá, como señaló Herder, algo intermedio entre una aldea y una ciudad cortesana.

Su condición de capital del nuevo Land de Turingia, desde el 1 de mayo de 1920, colmaba viejas aspiraciones dinásticas y aportó alguna vitalidad a la vida urbana. En cualquier caso, ya en 1924 el Gobierno de Turingia pasó a depender de la tolerancia del Partido Nacionalsocialista Alemán, que la condicionó a medidas de purificación racial; la presión política obligó a la Bauhaus a abandonar de inmediato Weimar e instalarse desde 1925 en Dessau. En 1930 entró por primera vez un nacionalsocialista en el gobierno de un Land; precisamente Wilhelm Frick como Ministro de Interior y de Educación de Turingia, que había participado en el golpe de Estado dado por Hitler en 1923 y a quien Hitler hizo Ministro de Interior cuando accedió a la Cancilleria en 1933. Las elecciones de 1932 convirtieron finalmente a Turingia en una región pionera de los procesos de nazificación. Hitler mismo, muy consciente del valor de Weimar, mantuvo un empeño constante en la resignificación del símbolo. Desde 1937, el campo de concentración de Buchenwald, en las inmediaciones de la ciudad, lleva a su extremo la ambigüedad de Weimar como referencia significativa.

Entretanto, Brecht llega a Berlín en 1924, desde 1928 dispone del Teatro am Schiffbauerdamm como centro de operaciones, de inmediato domina la escena cultural de la nueva Alemania; se desplaza desde la inicial inspiración en el expresionismo hacia la llamada "nueva objetividad", comienza en 1926 a desarrollar los postulados de su "teatro épico", desde 1929 lleva a escena sus "piezas didácticas". En 1931, con el poema que aquí aportamos, no se limita a glosar con distancia la Constitución de 1919. En realidad, la incorpora al lenguaje de la gran ciudad y del nuevo tiempo, a un mundo cultural que él mismo está contribuyendo a configurar de modo decisivo.

Cada Constitución, en efecto, es un fragmento vivo de cultura, que enraíza en la totalidad cultural del pasado y cobra sentido dentro del marco que ofrecen los desarrollos culturales de cada momento histórico: el de su aprobación inicial, el de su interpretación y aplicación actual, el de su proyección hacia el futuro como criterio normativo. La fuerza normativa de una Constitución depende fundamentalmente de tales contextos culturales: de su recepción y de su procesamiento por parte de la comunidad de juristas y de la comunidad política a la que se refiere, de su engaste con las respectivas tradiciones jurídicas y politicas, de las expectativas de futuro que en cada momento puedan ligarse a ella. Por eso, incluso cuando ya han sido liquidadas de uno u otro modo sus pretensiones inmediatas de vigencia normativa, cada Constitución se incorpora también a los presupuestos culturales de la fuerza normativa de las ulteriores, como una referencia inexcusable para su comprensión, su interpretación y su valoración.

Weimar, en este sentido, representa para la doctrina actual una herencia ambivalente: la de una Constitución relativamente lograda para una República 
que acabaría fracasando por razones cuya relación con el texto aprobado en 1919 resulta remota o, al menos, muy mediatizada; y también la de unos debates de gran altura en el plano de la teoría del Estado y del Derecho constitucional, que aún sirven como telón de fondo para las formulaciones actuales, y que sin embargo no lograron entonces dar soporte a la pretensión normativa de la Constitución vigente. A partir de algunos fragmentos del texto de Weimar, la tensión entre, de un lado, su interpretación canónica por parte de Gerhard Anschütz y, de otro, su incorporación, de la mano de Bertolt Brecht, en el espacio cultural que él mismo configura con su obra y su presencia, quizá pueda arrojar luz sobre tal ambivalencia.

\section{NOTA BIBLIOGRÁFICA.}

Los textos de Bertolt Brecht están tomados de la edición de sus obras completas (Gesammelte Werke) en la editorial Suhrkamp, Frankfurt am Main, 1967; el poema "Drei Paragraphen der Weimarer Verfassung", en el volumen 8, Gedichte I, pp. 378 ss.; el texto "Rechtsprechung", en el volumen 12, Prosa 2, págs. 391 s. Son aludidas también diversas traducciones de poemas suyos al castellano, como Poemas y canciones, Alianza, Madrid, 1968, versión de Jesús López Pacheco sobre la traducción directa del alemán de Vicente Romano, y Más de cien poemas, Hiperión, Madrid, 1998, selección y epílogo de Siegfried Unseld, traducción de Vicente Forés, Jesús Munárriz y Jenaro Talens. Su Teatro completo en castellano, ahora en un solo volumen, Cátedra, Madrid, 2012, en edición de Miguel Sáenz. La referencia a Marcel Reich-Ranicki procede de su prólogo ("Vorwort") al libro editado por él mismo Bertolt Brecht. Der Mond über Soho. 66 Gedichte mit Interpretationen, Insel, Frankfurt am Main/Leipzig, 2002, pp. 13 ss. Por lo demás, sobre Bertolt Brecht basta con referirse a Hans Mayer, Brecht, Suhrkamp, Estella-Navarra, 1998, que también analiza su relación con el clasicismo alemán (pp. 160 ss.) o con el marxismo (pp. 174 ss., 257 ss., etc.). Hans Mayer, por cierto, no solo fue un eminente teórico y crítico literario, sino también doctor en Derecho bajo la dirección de Hans Kelsen y colaborador entre otros de Max Horkheimer.

El texto de la solicitud de jubilación anticipada de Gerhard Anschütz se recoge en su libro Aus meinem Leben (edición e introducción de Walter Pauly), Vittorio Klostermann, Frankfurt am Main, 1993 (2 ${ }^{\text {a }}$ ed. 2008), págs. 328 s. La décimocuarta edición de su comentario sistemático a la Constitución de Weimar (Die Verfassung des Deutschen Reichs vom 11. August 1919), aquí profusamente utilizado, fue publicada en 1933 por la editorial Georg Stilke de Berlin y reimpresa en 1960 por Hermann Gentner Verlag de Bad Homburg vor der Höhe. Para la teoría del Estado y el Derecho constitucional en la Alemania de la época resultan decisivos Gerhard Anschütz, Richard Thoma (ed.), Handbuch des Deutschen Staatsrechts, J.C.B. Mohr (Paul Siebeck), Tübingen, 1930 (Bd. I) y 1932 (Bd. II); y Hans Carl Nipperdey (ed.), Die Grundrechte und Grundpflichten der Reichsverfassung, Reimar Hobbing, Berlin, Tomos I (1929), II (1930) y III (1930). Ya con alguna perspectiva histórica, Willibalt Apelt, Geschichte der Weimarer Verfassung, C.H. Beck, München und Berlin, 1964 ( $2^{\text {a }}$ ed., que recoge sin alteraciones la primera de 1946). Y luego, absolutamente imprescindible, Michael Stolleis, Geschichte des öffentlichen Rechts in Deutschland. Weimarer Republik und Nationalsozialismus, C.H. Beck, München, 1999. Cfr. también Christoph Gusy (ed.), Weimars lange Schatten - “Weimar" als Argument nach 1945, Nomos, Baden- 
Baden, 2003; y ahora, ya con la perspectiva del centenario, sobre todo Horst Dreier - Christian Waldhoff (eds.), Das Wagnis der Demokratie. Eine Anatomie der Weimarer Reichsverfassung, C.H. Beck, München, 2018; y Christoph Gusy, 100 Jahre Weimarer Verfassung: Eine gute Verfassung in schlechter Zeit, Mohr Siebeck, Tübingen, 2018.

La cita del Manifiesto comunista se toma de Karl Marx, Friedrich Engels, Manifest der kommunistischen Partei, ZK der SED, Berlin, 1973, p. 199. Sobre distancia y Derecho mencionamos a Eberhard Schmidt-Aßmann, "Der Rechtsstaat", en Josef Isensee, Paul Kirchhof (eds.), Handbuch des Staatsrechts der Bundesrepublik Deutschland. Band II, Verfassungsstaat, C.F. Müller, Heidelberg, 3 ${ }^{\mathrm{a}}$, ed., 2004, pp. 556 s. Sobre el clasicismo en Weimar hacemos alusión a Rüdiger Safranski, Goethe y Schiller. Historia de una amistad, Tusquets, Barcelona, 2011; un ensayo sobre la historia de la ciudad ha publicado recientemente Steffen Raßloff, Geschichte der Stadt Weimar, Sutton, Erfurt, 2018.

Nunca hubiera concebido un ensayo como este si antes no me hubiera deleitado con la lectura de los más hermosos trabajos de Michael Stolleis, como Der menschenfreundliche Ton. 24 Kalendergeschichten von Johann Peter Hebel mit kleinem Kommentar, Insel, Frankfurt, 2003; o, más recientemente, los que componen Margarethe und der Mönch. Rechtsgeschichte in Geschichten, C. H. Beck, München, 2015. Por lo demás, cualquier texto que se plantee la integración de las constituciones en los marcos generales de la vida cultural tiene como referencia inexcusable la formidable aportación de Peter Häberle, Verfassungslehre als Kulturwissenschaft, $2^{\mathrm{a}}$ ed., Duncker und Humblot, Berlin, 1998. En reconocimiento a su ubérrimo magisterio le dedico formalmente este ensayo, cuya última revisión se cierra precisamente el 13 de mayo de 2019, día de su 85 cumpleaños.

Enviado el (Submission Date): 13/04/2019

Aceptado el (Acceptance Date): 7/05/2019 